\title{
EL HECHIZO VIQUIANO
}

\section{Manuela Sanna (ISPF, del CNR)}

RESUMEN: La Autora relata el proceso autobiográfico de su descubrimiento de Vico, dentro del contexto napolitano de estudios en los años Ochenta. Un proceso en el que se desvela una razón narrativa histórica que, en la línea del historicismo antiesencialista de la Escuela napolitana, ha conducido a la Autora desde el estudio de la Ciencia nueva hasta la preparación de ediciones críticas de las obras de Vico.

PALABRAS ClaVE: Vico, $350^{\circ}$ Aniversario, naturaleza humana, sensibilidad, corporeidad, opera omnia, epistolario, Escuela napolitana, F. Tessitore, P. Cristofolini, G. Cacciatore, M. Sanna.

\section{The Vichian Spell}

ABSTRACT: The Author tells the autobiographical process of her discovery of Vico, within the Neapolitan context of studies in the eighties. A process in which a historical narrative reason is revealed: one that, in line with an nonessentialist historicism of the Neapolitan School, has led the Author from the study of the New science to the preparation of critical editions of Vico's works.

KEYWORDS: Vico, $350^{\text {th }}$ Anniversary, human nature, sensitivity, corporeity, opera omnia, correspondence, Neapolitan school, F. Tessitore, P. Cristofolini, G. Cacciatore, M. Sanna.

\section{L'incantesimo vichiano}

RIASSUNTO: L'Autrice ripercorre il processo autobiografico della sua scoperta di Vico nell'ambito del contesto napoletano di studi degli anni Ottanta. Un processo in cui emerge una ragione storico- narrativa che, nel solco dello storicismo anti-essenzialista della Scuola napoletana, ha condotto l'Autrice dallo studio della Scienza nuova alla preparazione delle edizioni critiche delle opere di Vico.

PAROle CHIAVE: Vico, $350^{\circ}$ Anniversario, natura umana, sensibilità, corporeità, opera omnia, epistolario, Scuola napoletana, F. Tessitore, P. Cristofolini, G. Cacciatore, M. Sanna.

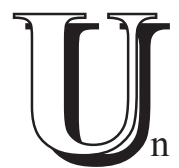

encuentro cercano con la propuesta filosófica de Giambattista Vico durante los años de la carrera universitaria no era -y quizá no es- una experiencia que se pudiese verificar con un alto grado de probabilidad, pero constituía por el contrario un acontecimiento muy verosímil en el seno del ateneo napolitano 
en el transcurso de los años Ochenta. No tanto por compartir territorio con nuestro ciudadano ilustre -como se sabe, ciertamente no profeta en su tierra-, cuanto, más bien, por la presencia de una sólida escuela napolitana que tenía como objetivo en aquellos años precisamente el redescubrimiento de la filosofía viquiana, y de aquello que fue lúcidamente llamado el "problema Vico". El problema, en síntesis, de liberar a Vico de una hegemonía idealista que estaba siendo releída y afrontada desde perspectivas nuevas. Mi primera lectura de la Ciencia nueva de 1744, la de la edición de Fausto Nicolini reeditada en los tipos de Laterza en 1974, no fue sugerida por una personal y autónoma curiosidad, sino más bien por la propuesta monográfica del examen de Historia de la Filosofía, la cátedra que en el ateneo napolitano ocupaba Fulvio Tessitore. En aquellos años la Facultad de Filosofía de Nápoles ensalzaba nombres ilustres de historiadores de la filosofía que proponían a los estudiantes una original reflexión "historicista", que encontraba justamente -o mejor, también- en la obra de Giambattista Vico y en el núcleo de su concepto de "historia" una pieza importante de esa vena histórico-filosófica que se estaba buscando. Mucho, no todo, giraba en torno a la dignidad XIV de la obra viquiana, según la cual «la naturaleza de las cosas no es otra que su nacimiento en ciertos tiempos y con ciertas maneras, las cuales, siempre que sean las mismas, de ellas las mismas cosas y no otras nacen», bajo la cual se escondían una consideración de la contextualización histórica y un distanciamiento sensible del concepto de naturaleza esencial que seguramente me han forjado. Y que me ha impulsado a valorar analíticamente el proceso por el cual las primeras facultades, aquellas que fundan la sociabilidad, son relativas solo a los sentidos y, en un segundo momento, también a la imaginación. En la importante fase no racional, para la cual no se prevé nunca una superación completa, está la posibilidad de pensar dentro de la filosofía viquiana la multiplicidad de las ideas de "humanidad" y la pluralidad de las historias humanas. En el momento del "nacimiento" no se actúa con la linealidad de la racionalidad, sino con el proceder incierto y arbitrario del sentido y de la imaginación, y esta constatación me dejaba entrever cómo el humanismo viquiano implicaba exactamente la imposibilidad de identificar una noción de "humano", abriéndose a una serie de características "verdaderamente humanas", y a la vez históricamente humanas.

Habiendo dedicado mi Tesina al concepto de historia en las obras latinas de G.W. Leibniz, ya afronté una idea de historia totalmente tejida por esa materia informe de la memoria, del deseo y de la relación del hombre histórico con su propia sensibilidad. Cuestiones todas que reencontraría también en el magma viquiano del concepto de naturaleza humana, que compartía con Leibniz ese movimiento imperceptible de insensibles percepciones que mucha literatura ha definido, en parte impropiamente, como una forma moderna de descubrimiento del "inconsciente". Y que revelaba una fórmula inédita de propuesta de ese modelo de sensi- 
bilidad totalmente moderna y profundamente humana que veía en el emerger de la consciencia fantástica e imaginativa una lectura innovadora y transformadora de la herencia renacentista.

Aquellos eran precisamente los años de la preparación de la edición crítica: las Oraciones inaugurales, con las que se abría el gigantesco proyecto de la edición crítica de la opera omnia, se publican justamente en 1982. Y en esos años se puede situar, por otro lado, la creación de aquel pequeño grupo de investigación que luego se convertiría en el "Centro di studi vichiani", y en torno al cual algunos jóvenes estudiantes comenzaban a curtirse fichando y reseñando materiales bibliográficos destinados al Bollettino del Centro di studi vichiani. Las reuniones en las aulas de la Academia pontaniana, las visitas -esporádicas pero muy intensas- a la casa de Pietro Piovani, el hallazgo de títulos para la Bibliografía en casa de Fausto Nicolini y de Benedetto Croce me indicaban un camino -a mí, sedienta de teoría y hermenéutica- que introducía sinérgicamente también un plano material, filológico, meramente textual. Un descubrimiento entusiasmante, que permitía moverse con agilidad entre ediciones príncipes y autógrafos, entre apostillas y escrituras de copistas, y que hacía emerger curiosidades y deseos no imaginados, desarrollaba competencias hasta entonces desconocidas, abría posibilidades inéditas.

Precisamente sobre la escribanía del editor crítico se afilaban las armas para afrontar ese "problema Vico" que Pietro Piovani indicaba como objetivo teórico: la lectura idealista, los trabajos anteriores de Croce y Nicolini, eran atenta y críticamente leídos y releídos, para poder luego emplear prudencia y circunspección en las elecciones hechas. Haberme regalado la posibilidad de ocuparme de las cartas relativas al epistolario viquiano cambió muchas cosas en mi carrera, la enriqueció y también la condicionó, desviándola de los proyectos iniciales, pero dándome la sorpresa del descubrimiento inesperado. Emergía un Vico en contacto con filósofos y científicos, hebraístas y lingüistas, para nada aislado -aunque sí a menudo polémicamente en desacuerdo-, provisto de muchos medios de acceso a la cultura transalpina. Un intelectual empeñado en intercambiar volúmenes, recensiones, opiniones, y buscar consensos, diálogos, comentarios, para alumbrar un buen conocimiento de quien venía de fuera de los confines del Reino napolitano.

Y desde la edición crítica del epistolario, no breve, sino ponderado, se pasó a la edición de las "Ciencias Nuevas". Ayudar a Paolo Cristofolini -con quien había contactado y conocido cuando yo trabajaba en la traducción italiana de Medicina mentis de Ernst von Tschirnahus- en la tarea de edición de la Ciencia nueva de 1730 y luego de la de 1744 me enseñó muchas cosas: ante todo, que trabajar con el escalpelo filológico unido a la formación filosófica ayuda muchísimo a entender la finalidad y el método de una edición creativamente crítica. Y después, que la fatiga resulta ampliamente compensada por el placer del trabajo y de la facilidad con la cual las palabras esconden tesoros a desenterrar. 
El encuentro con las lecturas anglosajonas, la nueva apertura a las investigaciones contemporáneas de los estudios de Giuseppe Cacciatore me empujaron a acercarme a Vico de nuevo y de manera distinta, frente a los estudios precedentes, y a intervenir sobre aquellas características teóricas que forjaron el Vico crociano inventor de la "estética" y que además hicieron de Vico un caso excepcional. Razonar sobre el tema del cuerpo y sobre sus transformaciones, lo cual puede ser sometido conjuntamente al concepto de verdad y a las grandes modificaciones que sufría el concepto de evidencia a la luz del clima cartesiano, es seguramente para mí el hechizo viquiano. Y es en el fondo, banalmente, un hilo conductor que permite reportar el pensamiento viquiano al diálogo con su contemporaneidad europea, en un vínculo de humores y perfumes más que de lecturas y testimonios probados. Un modo de andar hacia el descubrimiento de las fuentes implícitas sin renegar de todas las explícitas.

[Traducción del italiano por María José Rebollo Espinosa]

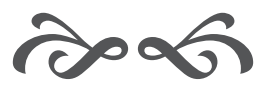

